\title{
Friction and Wear Performances of 7475 Aluminium Alloy after Anodic Oxidation
}

\author{
Kong Dejun, Wang Jinchun, Liu Hao \\ Jiangsu Key Laboratory of Materials Surface Science and Technology, Changzhou University, Changzhou 213164, China
}

\begin{abstract}
A layer of oxide film was prepared on the surface of 7475 aluminum alloy by anodic oxidation. The friction and wear performance of the film at different loads were investigated with the friction and wear tests. The atomic binding energy spectrum, the wear morphologies, the surface hardness and the residual stress were analyzed with XPS, SEM, hard meter and XRD stress tester, respectively. The results show that the oxide film on the surface is relatively dense after anodic oxidation, existing in the form of $\mathrm{Al}_{2} \mathrm{O}_{3}$, and diffusion type bonding is contained at the interface. The average friction coefficient is decreased after anodic oxidation, indicating that the friction performance is improved. The wear mechanism of the original sample is adhesive wear and tear, accompanied with abrasive wear, and the wear mechanism of the sample after the anodic oxidation is abrasive wear, where high surface hardness is the main factor of the wear resistance.
\end{abstract}

Key words: anodic oxide film; surface morphology; friction coefficient; wear performance

Because of high specific strength, corrosion resistance, easily machining and other excellent performances, aluminum alloy has been widely used in aerospace industry ${ }^{[1,2]}$. However, as friction material, aluminum alloy has high friction coefficient and wear volume, and it is easy to strain and difficult to lubrication ${ }^{[3]} .7475$ aluminum alloy is a new aluminum alloy of $\mathrm{Al}-\mathrm{Zn}-\mathrm{Mg}-\mathrm{Cu}$ that is strengthened with heat treatment, but it inevitably possesses some shortcomings of aluminum alloy. In order to improve the performances of aluminum alloy, the existing surface modification methods mainly include laser cladding, chemical plating Ni-P coating, micro arc oxidation, sol-gel method and etc. ${ }^{[4-9]}$ Anodic oxidation is referred to that in an appropriate electrolyte with metals as the anode, the dense oxide film is formed in the sample surface ${ }^{[10]}$ under the effect of impressed current. The typical anodic oxidation is sulfuric acid anodizing in which the sulfuric acid is used as the electrolyte and aluminum workpiece as anode, lead or aluminum as cathode. $\mathrm{Al}_{2} \mathrm{O}_{3}$ film prepared in the surface of aluminum alloy can improve its strong adhesion and surface hardness; as a result, the purpose of enhancing wear resistance can be achieved ${ }^{[11]}$. In the present investigation, the method of sulfuric acid anodizing was used to generate a layer of dense anodic oxide film in the surface of 7475 aluminum alloy, energy spectrum of oxidation film was analyzed with XPS, and the wear properties and friction coefficients were inspected, and the effects of surface hardness and residual stress on properties of the friction and wear were analyzed.

\section{Experiment}

The tested material was 7475 aluminum alloy with chemical compositions as follows (wt $\%$ ): $\mathrm{Si} \leq 0.10, \mathrm{Fe} \leq 0.12$, $\mathrm{Mn} \leq 0.06, \mathrm{Cu} 1.2 \sim 1.9, \mathrm{Mg} 1.9 \sim 2.6, \mathrm{Cr} 0.18 \sim 0.25, \mathrm{Ti} \leq 0.06, \mathrm{Zn}$ 5.2 6.2, Al balance. Anodic oxidation process included degreasing $\rightarrow$ removing the natural oxide film $\rightarrow$ chemical polishing $\rightarrow$ washing $\rightarrow$ heat sealing. The technological parameters were as follows: concentration of sulfuric acid was $180 \pm 2 \mathrm{~g} / \mathrm{L}$, aluminum ion concentration $5 \sim 10 \mathrm{~g} / \mathrm{L}$, the rest was water, temperature $20 \pm 0.5^{\circ} \mathrm{C}$, the current density $1.5 \pm 0.1$ $\mathrm{A} / \mathrm{dm}^{2}$. The stirring the method was used with compressed air, time was $45 \mathrm{~min}$, and the required samples were finished. The wear test was conducted on HRS-2M type reciprocating

Received date: May 19, 2015

Foundation item: the Science and Technology Support Project of Jiangsu Province, China (BE2012066)

Corresponding author: Kong Dejun, Ph. D., Professor, College of Mechanical Engineering, Changzhou University, Changzhou 213164, P. R. China, Tel: 0086-51981169810, E-mail: kong-dejun@163.com 
friction and wear tester, friction method included reciprocating, friction pair $\Phi 5 \mathrm{~mm}$ ceramic ball, respective loads $(600,800$, $1000 \mathrm{~g}$ ), reciprocating times (500 times/min), reciprocating length $(5 \mathrm{~mm})$. Friction coefficients were recorded automatically by the test software. Via testing friction coefficients before and after anodic oxidation and varying the applied load, the effect of load on friction coefficient was investigated. The worn morphologies and chemical elements before and after anode oxidation were analyzed by JSM-6360LA type SEM and EDS, respectively. Residual stresses were measured adopting roll fixed method, with $\mathrm{Cr}$ target $\mathrm{K} \alpha$ radiation, crystal of (311), starting and ending angle was $145^{\circ}, 135^{\circ}$, scanning step of $0.10^{\circ}$, counting time of $0.50 \mathrm{~s}$.

\section{Results and Discussion}

\subsection{Surface morphology and XPS analysis}

After anodic oxidation, the sample surface was covered with a dense $\mathrm{Al}_{2} \mathrm{O}_{3}$ oxide film, as shown in Fig.1a. There are some black spots on the surface after anodic oxidation, which are caused by enrichment phenomenon of $\mathrm{Si}$ and other insoluble materials, affecting the appearance quality of aluminum alloy. The essence of anodic oxidation is the electrolysis of water and the hydrolysis of the electrolyte which occurs under the function of current after energization. Hydrogen gas is generated at the cathode, and negatively charged anions move toward the anode, emitting electrons to produce oxygen. The parts of the oxygen react with anodic aluminum and the alumina membrane is generated. Fig. $1 \mathrm{~b}$ is the interface morphology of anodic oxide film. The diffusion at the interface is obvious to form a narrow white band where a mutual diffusion occurs, i.e. the $\mathrm{Al}$ atoms of the base metal diffuse into the oxide film and $\mathrm{O}$ atoms in the oxide film move to the base mental, which suggests that the interface of oxide film-substrate is diffusion combination.

As shown in Fig.2a, the peak of $\mathrm{Al} 2 \mathrm{p}$ at binding energy of $74.37 \mathrm{eV}$ represents the form of $\mathrm{Al}^{3+}$, corresponding to $\mathrm{Al}$ in $\mathrm{Al}_{2} \mathrm{O}_{3}$. The peak of $\mathrm{O} 1 \mathrm{~s}$ at binding energy of $531.82 \mathrm{eV}$ represents the form of $\mathrm{O}^{2+}$, as shown in Fig.2b, corresponding to $\mathrm{O}$ in $\mathrm{Al}_{2} \mathrm{O}_{3}$. With the oxidation going on, the dense oxide film presents atoms $\mathrm{O}$ from diffusing and slows down the oxidation of the oxide film and the base metal. As shown in Fig.2c, the $\mathrm{C} 1 \mathrm{~s}$ peak is located at $284.79 \mathrm{eV}$, which is presented in the form of $\mathrm{C}^{4+}$ combined with $\mathrm{O}$ to form $\mathrm{C}-\mathrm{O}$ and $\mathrm{C}-\mathrm{H}$ bonds.

\subsection{Friction coefficients}

Fig. 3 shows the friction coefficients-wear time curve under different loading conditions. The wear process can be divided into a fast rise stage, a fluctuation stage and a stability stage ${ }^{[12]}$. (1) The fast rise stage: the friction coefficient increases rapidly in this stage, which is due to the asperity on surface and uneven surface. (2) The fluctuation stage: friction coefficient fluctuates in a certain range and it is unstable, which is mainly because of the friction surface after the first stage. The friction coefficient is high, and with the continuous wear, a lot of friction heat is generated. (3) The stability stage: the friction coefficient tends

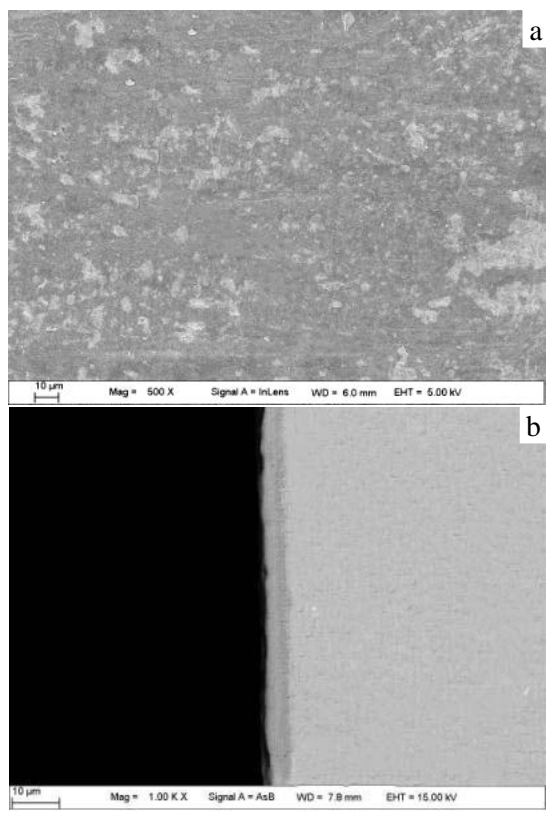

Fig.1 Surface (a) and interface (b) morphologies of anodic oxide film
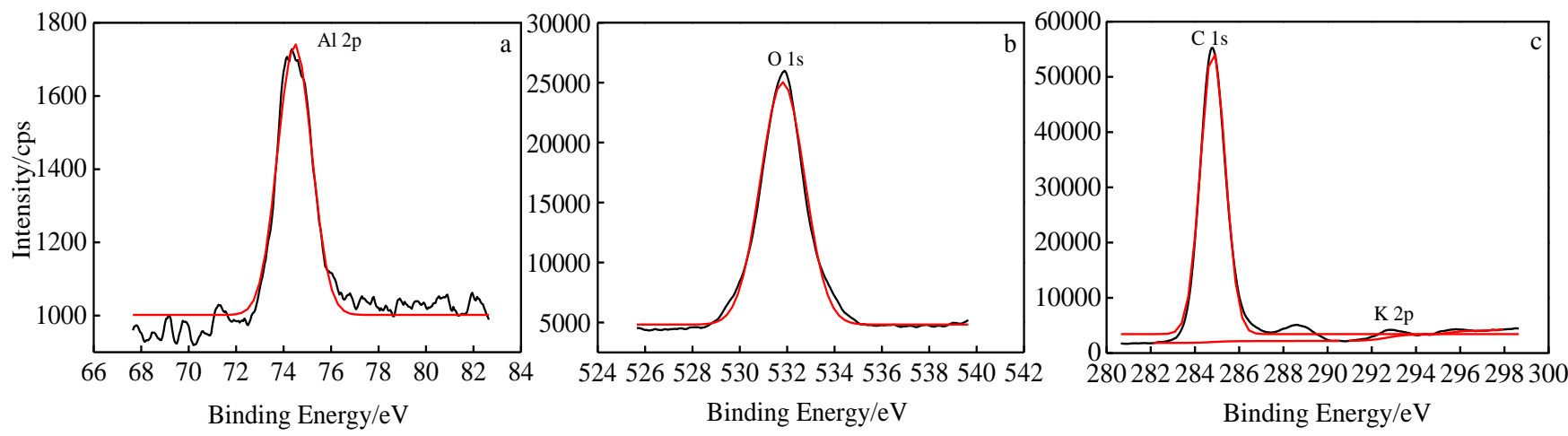

Fig.2 XPS spectra of chemical elements on the anodic oxide film: (a) Al, (b) O, and (c) C 

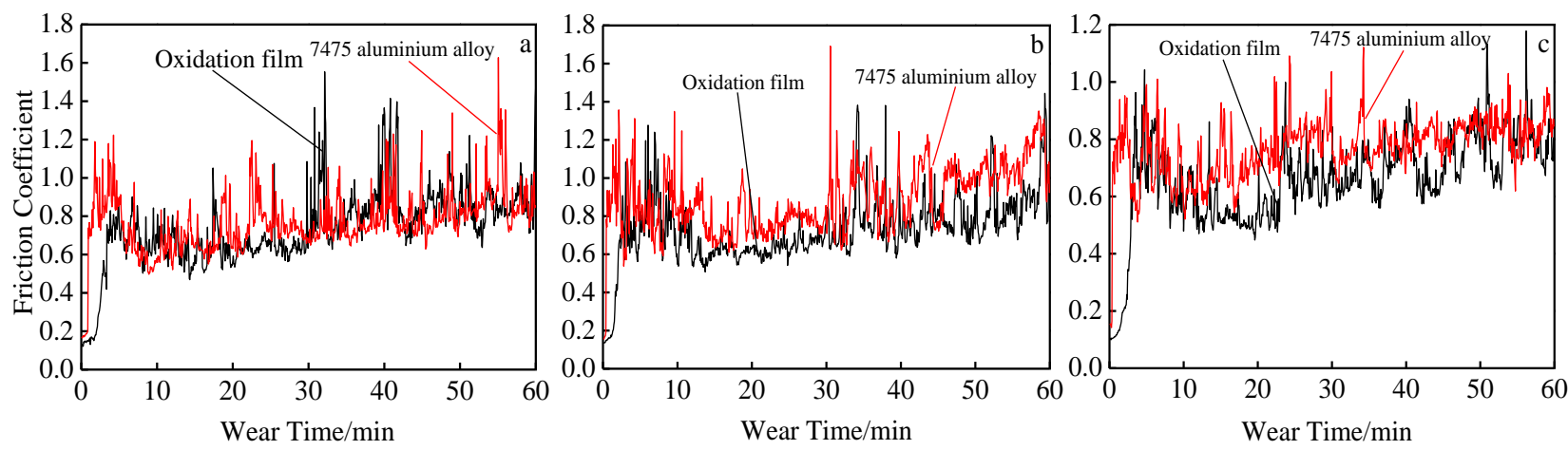

Fig.3 Friction coefficients vs wear time under different loads: (a) $600 \mathrm{~g}$, (b) $800 \mathrm{~g}$, and (c) $1000 \mathrm{~g}$

to be stable and enters the stage of normal wear after above two stages. The original sample and the sample after anodic oxidation are basically the same after the completion of the three stages. The difference is that the curve of the sample after anodic oxidation is a little lower in the longitudinal direction compared to the original state curve, indicating the friction coefficient decreases after anodic oxidation.

As shown in Fig.3a, when the load is $600 \mathrm{~g}$, the duration of fast rising stage is $0 \sim 5 \mathrm{~min}$, the one of fluctuation stage is 5 40 min and the one of stable stage is 40 60 min. The average friction coefficient of the original sample is 0.7663 , and the average friction coefficient of the sample after anodic oxidation is 0.7372 , reduced by $3.80 \%$. Fig. 3 b shows that when the load is $800 \mathrm{~g}$, the duration of fast rising stage is $0 \sim 4$ $\mathrm{min}$, the one of fluctuation stage is $4 \sim 35 \mathrm{~min}$ and the one of stable stage is $35 \sim 60 \mathrm{~min}$. The average friction coefficient of the original sample is 0.8872 , and the friction coefficient of the sample after anodic oxidation is 0.7278 , reduced by 17.97\%. As shown in Fig.3c, when the load is $1000 \mathrm{~g}$, the duration of fast rising stage is $0 \sim 3 \mathrm{~min}$, the one of fluctuation stage is 3 30 min and the one of stable stage is 30 60 min. The average friction coefficient of the original state sample is 0.7658 , and the average friction coefficient after anodic oxidation is 0.6591 , reduced by $13.93 \%$. Therefore, the heavier the load is, the less the time of the normal wear stage is.

\subsection{Worn morphologies}

Fig.4 shows the worn morphologies of the original sample surface under different loads, and there are some adhesions on the surfaces. With the increase of load, the worn surface morphology changes. As shown in Fig.4a, when the load is $600 \mathrm{~g}$, there are fine abrasives, some adhesive material and a small amount of furrows parallel to the sliding direction. The formation of the furrows is due to not timely detachment on the contact of soft aluminum alloy surface scratch. In Fig.4b, when the load is $800 \mathrm{~g}$, the amount of adhesions on the worn surface is more than those under the load of $600 \mathrm{~g}$ but with less furrows. As shown in Fig.4c, under the load of $1000 \mathrm{~g}$, furrows on the worn surface basic disappear, while a large adhesive area appears and there are lots of focal adhesion complexes. This is mainly because the further increase of load the frictional heat is generated more and more, resulting in the friction and the aluminum alloy more likely to adhering.

Fig.5 shows the worn morphologies of the sample surfaces after anodic oxidation under different loads. Compared with the surface morphologies in Fig.4, after wear there are some scratches and drop pits without furrows on the worn surface under the same load. With the change of the load, the worn surface morphology changes. As shown in Fig.5a, as the load is $600 \mathrm{~g}$, there are less drop pits and shallow scratches on the worn surface. Fig.5b shows that under the load of $800 \mathrm{~g}$, the depth and the width of scratches on the worn surface become big and the number of drop pits become smaller. As shown in Fig.5c, the
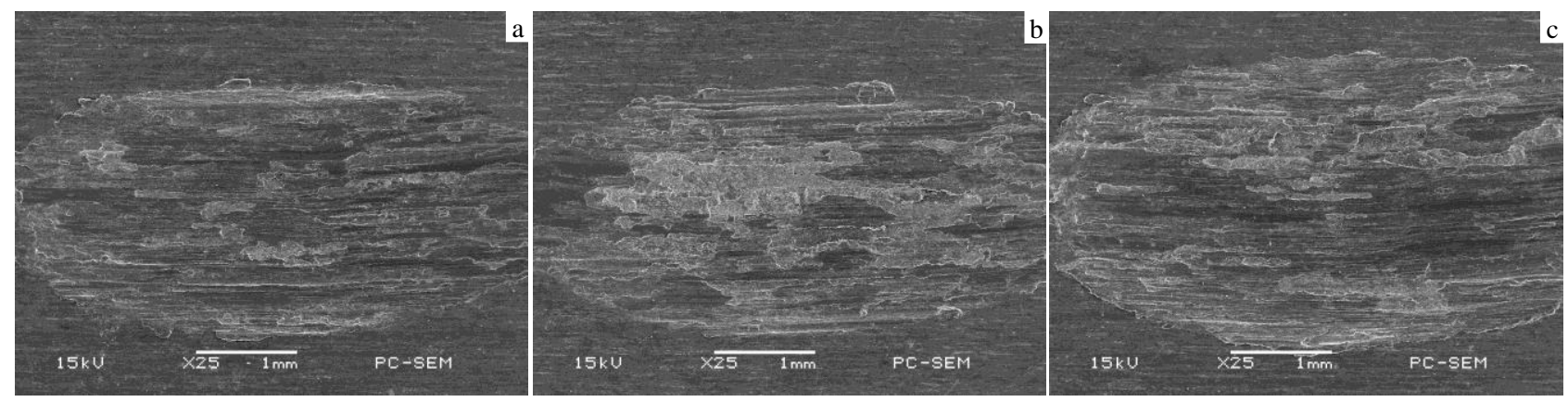

Fig.4 Worn morphologies of the original sample surface under different loads: (a) $600 \mathrm{~g}$, (b) $800 \mathrm{~g}$, and (c) $1000 \mathrm{~g}$ 

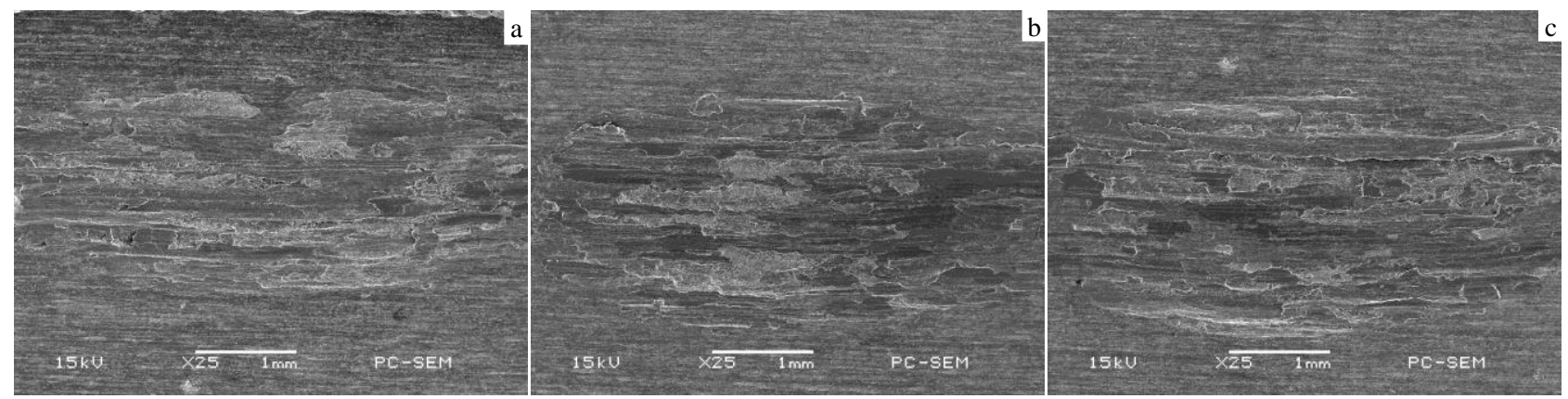

Fig.5 Worn morphologies of the sample surface after anodic oxidation under different loads: (a) $600 \mathrm{~g}$, (b) $800 \mathrm{~g}$, and (c) $1000 \mathrm{~g}$

load is $1000 \mathrm{~g}$, there are a large number of scratches, which become wider and deeper with a large number of pits, showing that the larger the load is, the more serious the worn surface is.

\subsection{Wear failure mechanisms}

Fig.6a shows the surface morphology of the original sample after wear, in which the furrows and adhesions exist on the worn surface with the sign of falling off (Fig.6b). The wear mechanism is adhesive wear accompanied with slight abrasive wear. During wear, friction heat is increased which leads to local surface melting due to the aluminum alloy soft texture. When the adhesion is enhanced, the cold welding points in the friction welding are formed, leading to the sample surface strip ping ${ }^{[13]}$. The atomic fractions (at\%) are shown in Fig.6c: Al 81.41, O 10.74, Mg 3.14, Si 4.10, Zn 0.43, Cu 0.18, indicating that the worn surface is given priority to $\mathrm{Al}$ and $\mathrm{O}$, and the rest is $\mathrm{Mg}, \mathrm{Si}, \mathrm{Zn}$ and $\mathrm{Cu}$ that come from the substrate.

Fig.7 shows the surface morphologies and EDS analysis of oxidation film after wear. There are no micro-cracks and a large number of scratches and drop pits is due to the small pores, impurities and other defects of the film. The asperities on the surface are dislocated or fall off under the action of the large instantaneous shear force. The $\mathrm{Al}_{2} \mathrm{O}_{3}$ film is a kind of hard and brittle ceramic membrane. According to Bifano's ductile removal mechanism of hard and brittle material ${ }^{[14,15]}$, when the cutting depth is less than a critical value, the brittle failure would be avoided. Once the cutting depth exceeds the critical value, macroscopic cracks are produced on the film. In the grinding process, when the maximum undeformed chip thickness $h_{\max }$ is less than critical shear ductile removal depth $h_{\mathrm{c}}$, the ground surface is formed by a plurality of abrasive micro film plastic removal of superimposion. Otherwise, the opposite brittle fracture occurs. Critical depth of brittle/ductile machining is as follows:

$$
h_{\mathrm{c}}=\beta \frac{E}{H}\left(\frac{K_{\mathrm{IC}}}{H}\right)^{2}
$$

where $\beta$ is constant; $E$ is the elastic modulus of ceramic materials; $K_{\mathrm{IC}}$ is the fracture toughness of ceramic materials; $H$ is material hardness.

When the hard phase falls off as the secondary grinding mill in the wear process, the wear is intensified, leading to the emergence of a large number of wear surface scratches and pits flaking off. The atomic fractions (at\%) are shown as follows: Al 65.20, O 27.49, Mg 3.14, Si 3.35, $\mathrm{Zn} \mathrm{0.52,} \mathrm{Cu}$ 0.21 , indicating that the worn surface is given priority to $\mathrm{Al}$ and $\mathrm{O}$ and a small amount of $\mathrm{Si}$ and $\mathrm{Mg}$ is contained, and $\mathrm{Mg}$ element is not shown.

\subsection{Analysis and discussions}

The hardness $\mathrm{HB}$ of the original sample is $1500 \mathrm{MPa}$ measured with HV-1000 type microhardness tester, while that of the anodic oxide film is $3800 \sim 4200 \mathrm{MPa}$, indicating that hardness of aluminum alloy is significantly improved after anodic oxidation. The dense $\mathrm{Al}_{2} \mathrm{O}_{3}$ film is formed on aluminum alloy surface, which is the mechanism of the
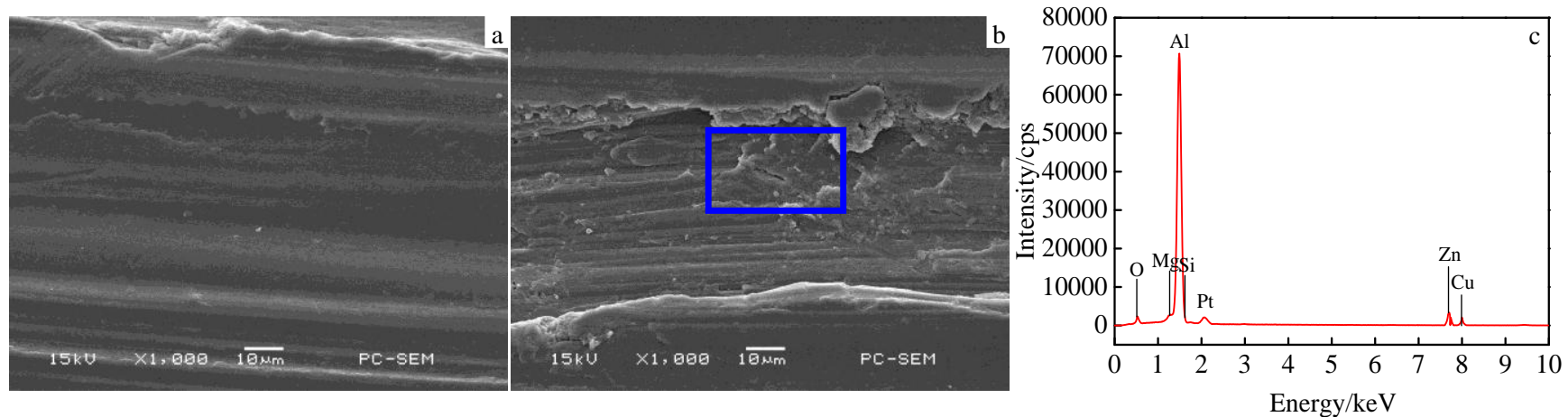

Fig.6 Surface morphologies of original sample after wear: (a) furrows, (b) falling off, and (c) EDS spectrum of surface after wear 

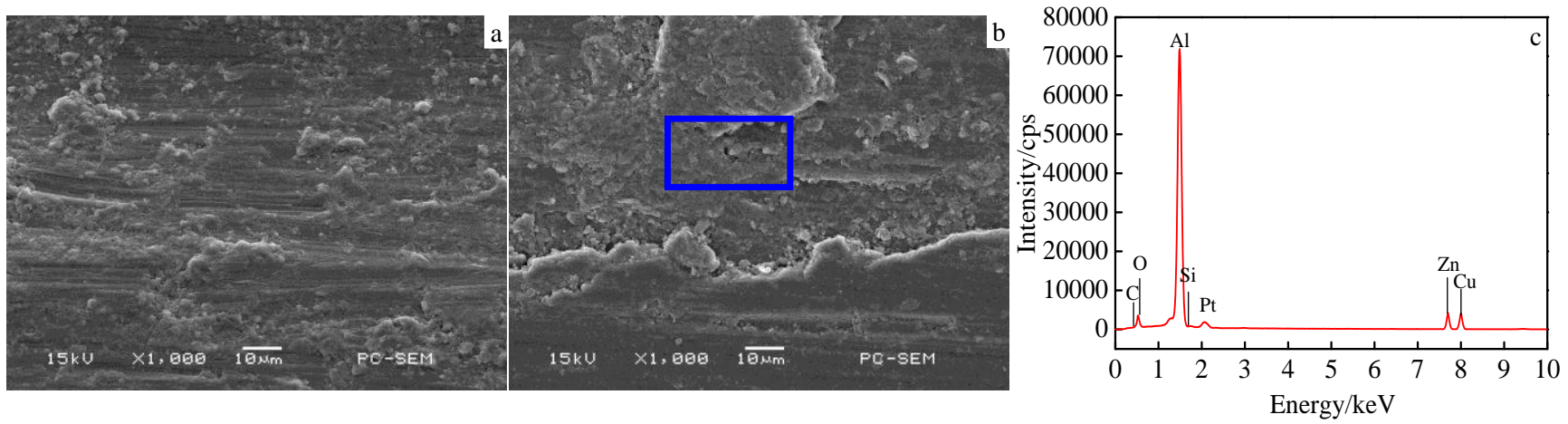

Fig.7 Morphologies and EDS analysis of anodic oxide film after wear: (a) abrasive wear, (b) falling off, and (c) EDS spectrum

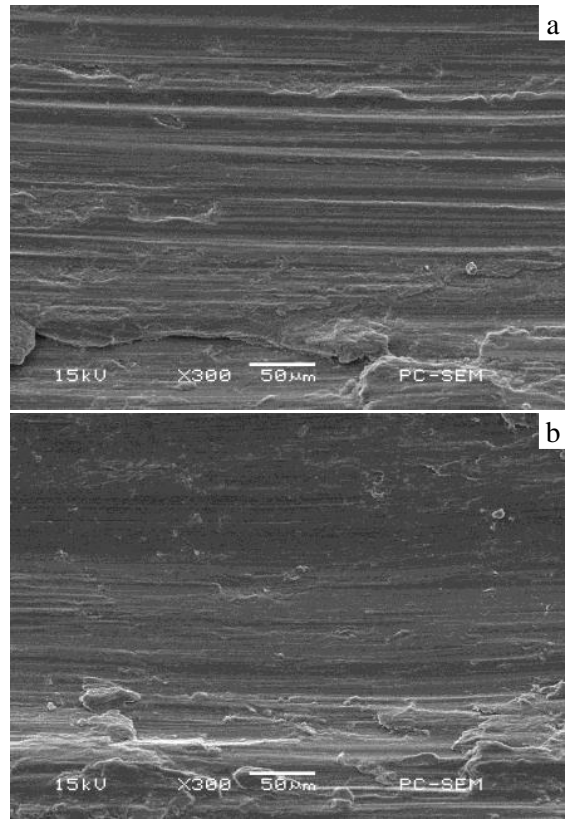

Fig.8 Worn morphologies before (a) and after (b) anodic oxidation

increased surface hardness. As shown in Fig.8a, there are a large number of furrows on the original sample surface. But there are shallower and narrower scratches on the worn surface after anodic oxidation, as shown in Fig.8b. As a result, high hardness of anodic oxide film improves the abrasion resistance.

The residual stress of the sample in the original state is 49 $\mathrm{MPa}$, which is compressive stress, as shown in Fig.9a. The residual stress of the anodic oxide film is $38 \mathrm{MPa}$, which is tensile stress, as shown in Fig.9b. Tensile stress after anodic oxidation is mainly due to the generation of anodic oxide film with metastable phase $\gamma-\mathrm{Al}_{2} \mathrm{O}_{3}$, which has amorphous structure. The different sizes of particles and no consistent contraction also result in the tension stress in the anodic oxide film. Tensile residual stress is easy to produce fatigue cracks on the sample surface, which weakens the wear resistance of the surface. However, in consideration of high hardness of oxide
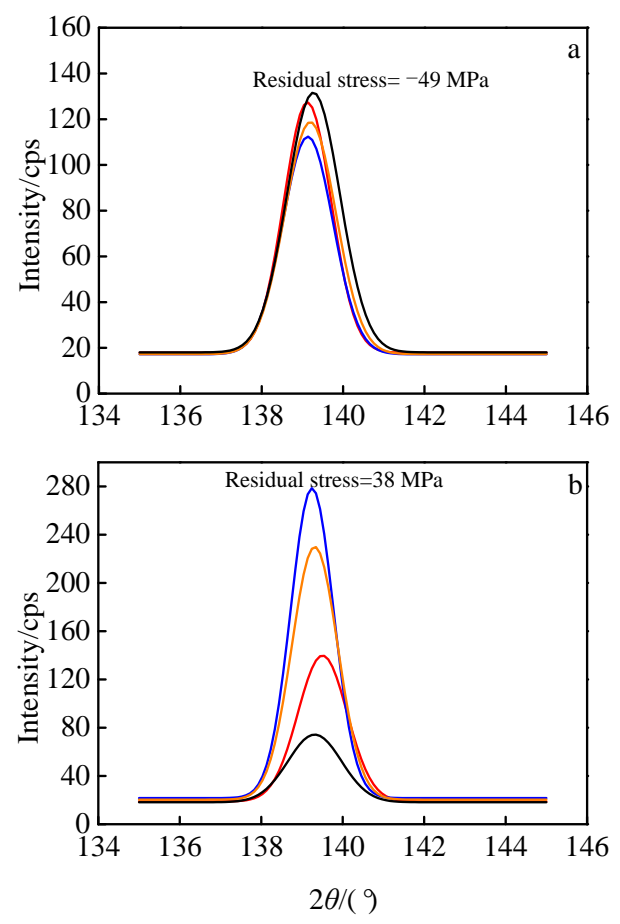

Fig.9 Residual stress before (a) and after (b) anodic oxidation

film, the effect of residual stress on friction and wear behavior can be negligible.

\section{Conclusions}

1) The peak of $\mathrm{Al} 2 \mathrm{p}$ at binding energy of $74.37 \mathrm{eV}$ represents the form of $\mathrm{Al}^{3+}$, while the peak of $\mathrm{O} 1 \mathrm{~s}$ at binding energy of $531.82 \mathrm{eV}$ represents the form of $\mathrm{O}^{2-}$, and the corresponding product $\mathrm{A}_{2} \mathrm{O}_{3}$.

2) The friction coefficients of anodic oxide films under the loads of $600,800,1000 \mathrm{~g}$ decrease by $3.80 \%, 17.97 \%, 13.93 \%$, respectively.

3) The wear mechanism of the original sample is adhesive wear and tear accompanied with abrasive wear, while the wear mechanism of anodic oxide film is abrasive wear. 
4) Anodic oxidation increases surface hardness, tensile residual stress is produced, and high hardness is an important factor to improve wear resistance.

\section{References}

1 Wang Yuan, Wang Meiling, Zhou Fei et al. The Chinese Journal of Nonferrous Metals[J], 2007, 17(8): 1266 (in Chinese)

2 Tolga Dursun, Costas Soutis. Materials and Design[J], 2014, 56: 862

33 Jannica H, Staffan J. Wear[J], 2011, 27: 2517

4 Yue T M, Huang K J, Man H C. Surface \& Coatings Technology [J], 2005, 194: 232

5 Hua Guoran, Huang Yinhua, Zhao Jianfeng et al. The Chinese Journal of Nonferrous Metals[J], 2004, 14(2): 199 (in Chinese)

6 Kong Dejun, Fu Guizhong. The Chinese Journal of Nonferrous Metals[J], 2012, 22(5): 1360 (in Chinese)

7 Sun Zhihua, Liu Ming, Guo Dapeng et al. Rare Metal Materials and Engineering[J], 2010, 39(1): 64 (in Chinese)
8 Shen Dejiu, Li Guolong. Applied Surface Science[J], 2013, 287: 451

9 Zhang Xuejun, Gao Chunxiang, Wang Lei et al. Rare Metal Materials and Engineering[J], 2010, 39(2): 367 (in Chinese)

10 Luo Liechao, Zhao Ronggen, Meng Jia et al. Journal of Inorganic Materials[J], 2002, 17: 1269

11 Chen Suiyuan, Yang Yongze, Liang Jing et al. Journal of Northeastern University, Natural Science Edition[J], 2010, 31: 1721 (in Chinese)

12 Kong Dejun, Wu Yongzhong, Wang Xiaofeng. Journal of Central South University, Natural Science Edition[J], 2012, 43 3472 (in Chinese)

13 Zhu Minghao, Zhou Zhongrong. Journal of Tribology[J], 2003, 23: 320

14 Bifano T G, Dow T, Scattergood R O. Journal of Engineering for Industry[J] , 1991, 113: 184

15 Xie Guizhi, Shang Zhentao, Sheng Xiaomin et al. Journal of Mechanical Engineering[J], 2011, 47: 169

\title{
7475 铝合金阳极氧化膜摩擦与磨损性能
}

\author{
孔德军，王进春，刘 浩 \\ (常州大学 江苏省材料表面科学与技术重点实验室, 江苏 常州 213164)
}

\begin{abstract}
摘 要: 采用阳极氧化法在 7475 铝合金表面制备一层氧化膜, 在摩擦磨损试验机上考察不同载荷情况下氧化膜摩擦磨损性能。利用 XPS、 扫描电镜、硬度计和 X 射线应力仪对膜层原子结合能谱、阳极氧化前后表面磨损形貌、表面硬度变化和表面残余应力变化进行了分析。 结果表明, 阳极氧化后表面较致密, 氧化膜是以 $\mathrm{Al}_{2} \mathrm{O}_{3}$ 形式存在, 其界面为扩散型结合形式; 阳极氧化后平均摩擦系数减小, 摩擦性能 得到提高; 原始状态试样的磨损机理为粘着磨损，并伴随着磨粒磨损，而阳极氧化后试样的磨损机理为磨粒磨损; 表面的高硬度是提高 耐磨性能的主要因素。
\end{abstract}

关键词: 阳极氧化膜; 表面形貌; 摩擦系数; 磨损性能

作者简介: 孔德军, 男, 1966 年生, 博士, 教授, 常州大学机械工程学院, 江苏 常州 213164, 电话: 0519-81169810, E-mail: kong-dejun@163.com 